\title{
Prevalence of type 2 diabetes and impaired fasting glucose: cross-sectional study of multiethnic adult population at the United States-Mexico border
}

\author{
Beatriz A. Díaz-Apodaca, ${ }^{1}$ Shah Ebrahim, ${ }^{2}$ Valerie McCormack, ${ }^{3}$ \\ Federico G. de Cosío, ${ }^{4}$ and Rosalba Ruiz-Holguín ${ }^{5}$
}

Suggested citation

Díaz-Apodaca BA, Ebrahim S, McCormack V, de Cosío FG, Ruiz-Holguín R. Prevalence of type 2 diabetes and impaired fasting glucose: cross-sectional study of multiethnic adult population at the United States-Mexico border. Rev Panam Salud Publica. 2010;28(3):174-81.
ABSTRACT

ective. To estimate prevalence of type 2 diabetes (diabetes) and impaired fasting glucose (IFG) in the border region between the United States of America and Mexico, by ethnic origin and country of residence; identify risk factors associated with both conditions; and explore the extent to which these factors account for cross-border or ethnic disparities in prevalence.

Methods. From April 2001 to November 2002, Phase I of the U.S.-Mexico Border Diabetes Prevention and Control Project, a prevalence study of diabetes and its risk factors, was conducted at the U.S.-Mexico border using multi-stage cluster sampling. A questionnaire was administered on diabetes (self-reported) and lifestyle and a physical examination and blood sample were obtained. A total of 4027 adults participated in the study: 2120 Hispanics from the Mexican side of the border and 1437 Hispanics and 470 non-Hispanics (of whom 385 were classified as "white") from the U.S. side of the border.

Results. The age-adjusted prevalence of self-reported and unrecognized diabetes in Hispanics was $15.4 \%$ (16.6\% on the Mexican side of the border and $14.7 \%$ on the U.S. side). The ageadjusted prevalence of IFG was similar on both sides of the border (14.1\% on the Mexican side and $13.6 \%$ on the U.S. side).

Conclusions. Established risk factors for diabetes (e.g., age, obesity, and family history) were relevant and there was an inverse relationship between diabetes and education and socioeconomic level. While diabetes prevalence is high on both sides of the U.S.-Mexico border, onefourth of the cases remain undiagnosed, suggesting a need for development and implementation of a public health program for prevention, diagnosis, and control of diabetes in the region.

Key words Diabetes mellitus, type 2; prevalence; border health; Mexico; United States.
Biomedical Sciences Institute, Department of Research and Graduate Studies, Universidad Autónoma de Ciudad Juárez, Juárez, Chihuahua, Mexico. Send correspondence to Beatriz DíazApodaca,bdiaz@uacj.mx

2 London School of Hygiene and Tropical Medicine, London, United Kingdom.

3 International Agency for Research on Cancer, Lyon, France.

4 Chronic Disease Program, Pan American Health Organization, Washington, D.C., United States of America.
Type 2 diabetes mellitus (diabetes) is recognized as a worldwide public health problem due to the high medical and socioeconomic costs that result from complications associated with the disease. It

\footnotetext{
U.S.-Mexico Border Diabetes Prevention and Control Project, Pan American Health Organization/ World Health Organization U.S.-Mexico Border Office, El Paso, Texas, United States of America.
}

is estimated that about 333 million people worldwide will be affected with diabetes by 2025 (1). The predictions of this rapid increase are based on various environmental and lifestyle trends, such as increasingly unhealthy diets and less physical activity, and the consequent increase in obesity. People with diabetes face an increased risk of cardiovascular, 
peripheral vascular, and cerebrovascular diseases, conditions that can lead to morbidity, disability, and premature death (2). Identified risk factors for diabetes include ethnicity, age, high body mass index (BMI) scores and central obesity indicators (waist-to-hip ratio and waist circumference), low birth weight, and "Westernization" (adoption of lifestyle habits characteristic of the more industrialized countries) (3-6). Hyperlipidemia and hypertension, along with obesity and cigarette smoking, have also been documented as preceding the onset of diabetes (7). An inverse association between socioeconomic status and diabetes prevalence in the middle years of life (8-10), which may be partly attributable to adverse health behaviors, has also been reported.

Diabetes is common in Mexico, where it has an age-adjusted national prevalence of $8.2 \%$ (11) and was reported as the underlying cause in $13.2 \%$ of deaths in 2004 and therefore the leading cause of mortality during that year (12). In the United States of America, diabetes has an age-adjusted national prevalence of $5.1 \%$ and it was the sixth leading cause of death in 2004 (13). Mortality rates and prevalence for diabetes differ between ethnic groups. In the United States, Hispanics are one of the worst affected groups, with an overall prevalence almost double that of non-Hispanics $(9.8 \%$ versus $5.0 \%$ ) and a higher age-adjusted prevalence than non-Hispanic whites (14-16). In 2002, $5 \%$ of deaths in U.S. Hispanics and $2.2 \%$ of deaths in U.S. non-
Hispanic whites were attributed to diabetes (17).

The U.S.-Mexico border region, which comprises $3169 \mathrm{~km}$ between the Pacific Ocean and the Gulf of Mexico, has a unique and diverse concentration of people, economies, and disease burdens as a consequence of the union of two very different countries: one middle-income and the other highly developed. Expectations of better employment opportunities and improved living conditions in the region have resulted in high levels of urbanization as well as migration. The U.S. side of the border has a higher proportion of Hispanics $(\sim 71 \%)$ than other parts of the United States. (18). When the health and sociodemographic characteristics of the Mexican and U.S. sides of the border are compared with those of Mexico and the United States, respectively, important differences can be observed (Table 1). While Mexican border states have a higher standard of living and longer life expectancy than the rest of Mexico, they also have higher mortality from chronic diseases, including diabetes, cardiovascular diseases, and cancer. The opposite trend exists for the U.S. side of the border, which is characterized by higher poverty and unemployment rates, and a lower rate of health insurance coverage. For example, diabetes was the fifth leading cause of death in New Mexico (19), the sixth in Texas (20), and the seventh in California (21) and Arizona (22) but the sixth leading cause of death nationwide in the United States. In 2006, in the six Mexican border states,

TABLE 1. Sociodemographic characteristics and diabetes mortality and prevalence in the United States, Mexico, and the U.S.-Mexico border region from various sources, 2001-2005

\begin{tabular}{|c|c|c|c|}
\hline Characteristic & United States & Mexico & U.S.-Mexico border region \\
\hline Total population & $296410404^{a}$ & $103263388^{b}$ & $13087452^{a, b}$ \\
\hline Hispanic population & $14.5 \%^{\mathrm{a}}$ & $98.0 \%$ b & $\begin{array}{c}\text { 63.3\% (U.S. side); } \\
\text { 99.0\% (Mexican side) }\end{array}$ \\
\hline Language & English & Spanish & English and Spanish \\
\hline Education (population with & & & \\
\hline$\geq 16$ years of schooling) & $84.2 \%{ }^{a}$ & $13.6 \%{ }^{b}$ & $N A^{c}$ \\
\hline Annual population growth & $1.3 \% \mathrm{a}, \mathrm{b}$ & $1.0 \%{ }^{b}$ & NA \\
\hline Diabetes rank as cause of death & 6 th $^{d}$ & $2 n d^{e}$ & $\begin{array}{l}\text { 2nd (Mexican side); } 5 \text { th to 7th } \\
\text { (U.S. side, varying by } \\
\text { border state })^{f}\end{array}$ \\
\hline Diabetes prevalence & $5.1 \%$ d & $8.2 \%$ & $\begin{array}{c}16.6 \% \text { ( } 8.8 \% \text { for non-Hispanic } \\
\text { whites and } 14.7 \% \text { for Hispanics })^{9}\end{array}$ \\
\hline
\end{tabular}

\footnotetext{
a U.S. 2005 Census.

b Mexican National Institute of Statistics and Geography (Instituto Nacional de Estadística y Geografía, INEGI), 2005.

c NA: not applicable.

d U.S. Centers for Disease Control and Prevention.

e Mexican ministry of health.

f Data based on references 18-22.

g Based on the results of Phase I of the U.S.-Mexico Diabetes Prevention and Control Project ( $n=4$ 027), 2001-2002.
}

diabetes was the third leading cause of death (23).

Despite the fact that diabetes appears to be a significant health problem in the U.S.-Mexico border region, few studies have examined its extent and determinants in a single, systematic way, using the same definitions and procedures, on both sides of the border. In the current study, a population-based survey was conducted on both sides of the entire U.S.-Mexico border region to determine the prevalence of diabetes, the characteristics of individuals affected by diabetes and impaired fasting glucose (IFG), and the key underlying risk factors of diabetes in the U.S.-Mexico border region.

\section{MATERIALS AND METHODS}

A population-based cross-sectional survey was conducted on both sides of the U.S.-Mexico border between April 2001 and November 2002. Based on population estimates from the 1990 Mexican and U.S. censuses, communities with a population of at least 2500 were eligible to participate. Stratified, clustered, multistage probability sampling with substitution was used to select study participants from sampling units based on geographic area. In the United States, census tracts within communities were divided into two strata based on 1990 population estimates of ethnicity. One individual aged 18 years or older in each enumerated household was selected to participate in the study using the "most recent birthday" criterion.

Potential interviewers were selected by the state and local agencies who participated in the project. On the U.S. side, interviewers had to be bilingual and included nurses, community health workers, and university students, whereas on the Mexico side interviewers consisted of physicians and nurses.

A questionnaire was administered face-to-face by a trained interviewer at each participant's home. As mentioned above, on the U.S. side, interviewers were fluent in both English and Spanish, so participants could complete the survey in either language based on their personal preference. Signed consent forms were obtained from all participants before administration of the questionnaire. Data was collected for six survey sections with a total of 65 questions covering general knowledge of diabetes, health and medical services, lifestyle 
(physical activity, diet, and tobacco and alcohol use), reproductive health, and sociocultural characteristics.

Following completion of the interview, anthropometric measurements were taken. Body weight and height were measured (with participants wearing light clothing and without shoes). BMI was calculated as weight $(\mathrm{km})$ divided by square of height $(\mathrm{m})$. Blood pressure was measured after a 15-minute rest period, with subjects in the seated position. Three readings for both systolic and diastolic pressure were recorded over a 5-minute interval and the average measurements were used in the analyses.

Fasting blood samples were taken the morning after a fast of at least eight hours. Blood samples were centrifuged and stored locally at $-20^{\circ} \mathrm{C}$ prior to being packed in ice and transported by air to the central laboratory in each country (the University of Missouri Diabetes Diagnostic Laboratory, in the United States, and the Nuevo León State Laboratory in Mexico). Plasma glucose was measured using the Cobas Mira Chemistry System (Roche Diagnostic Systems, Inc., Montclair, NJ, USA), a Sorvall GLC-2B centrifuge (DuPont Instruments, Wilmington, DE, USA), and a Jouan GR4-22 refrigerated centrifuge (Valley Biomedical, Winchester, VA, USA). Glycosylated hemoglobin A1c was analyzed with the Primus Automated CLC-385 HPLC system, model CLC385 (Primus IV, Kansas City, MO, USA). Laboratory personnel from both countries were trained by staff from both of the central laboratories and Primus. To ensure the integrity of the laboratory results, both laboratories used the same equipment and the same specifications. For simultaneous quality control, both laboratories exchanged 20 samples every three months. Samples were tested in both countries and the results were compared between laboratories. The laboratories agreed to accept a 3\% variance in the results. If the discrepancy was higher than 3\%, Primus technicians were sent to both laboratories to evaluate and resolve the problem.

A field test of the protocol was carried out in February 2001 in two border cities (El Paso, Texas, and Ciudad Juárez, Chihuahua). Ethical clearance was obtained from both the U.S. Centers for Disease Control and Prevention (CDC) and the Mexican ministry of health.

Study participants were classified as having diabetes if they 1 ) reported a pre- study diagnosis of diabetes from a doctor or other health care professional and/ or 2) had a fasting plasma glucose value $\geq 7.0 \mathrm{mmol} / \mathrm{L}$ (126 mg/ dL). Those classified as having diabetes were then subclassified accordingly as having either "known diabetes" (based on previous diagnosis) or "newly diagnosed diabetes" (based on the $\geq 7.0 \mathrm{mmol} / \mathrm{L}$ fasting plasma glucose value plus the participant's assertion that he/she was not previously aware of having the disease).

In accordance with World Health Organization (WHO) criteria (24), study participants were classified as having impaired fasting glucose (IFG) if they had a fasting plasma glucose value of 5.6-6.9 $\mathrm{mmol} / \mathrm{L}$ (100-125 mg/dL) but no previous diagnosis of diabetes. Self-reported alcohol consumption and smoking status were estimated from participants' responses to the questionnaire. Alcohol consumption was classified as "never," "occasional" (< 30 drinks per month), or "heavy" (> 30 drinks per month), whereas smoking status was classified as "never smoked," "former smoker," or "current smoker." Systolic and diastolic blood pressure measurements were grouped according to the 2003 National Committee on Prevention, Detection, Evaluation, and Treatment of High Blood Pressure (25). A family history was considered positive for diabetes if at least one parent or one sibling had been diagnosed with the disease. Ethnic origin was classified as "Hispanic" for those who were born in Mexico or identified themselves as Hispanics. "Non-Hispanic whites" were defined as those who were born in the United States and identified themselves as non-Hispanics, and the category labeled "Other" comprised those who identified themselves as both nonHispanic white and non-Hispanic.

\section{Statistical analysis}

The characteristics of the three subject groups (Hispanics in Mexico, Hispanics in the United States, and non-Hispanic whites in the United States) are expressed as means plus standard deviation (SD) or absolute frequency and percentages, as appropriate. Age-adjusted prevalence of diabetes was obtained using the direct adjustment method of standardization based on the WHO standard population for the year 2000 (26). To identify associations between potential risk factors and diabetes and IFG, crude and age-adjusted odds ratios (ORs) were obtained using multiple logistic regression models. For differences between groups, analysis of variance and multinomial models were used. All statistical analyses were performed using STATA 10 for Windows (StataCorp LP, College Station, Texas, USA).

\section{RESULTS}

Of the original sample pool of 4240 individuals $\geq 18$ years of age, 4027 participated in the study: 2120 Hispanics from the Mexican side of the border $(98.0 \%$ response rate) and 1437 Hispanics and 470 non-Hispanics from the U.S., side of the border (89.0\% response rate), with 385 of the latter group classified as nonHispanic white. Out of these 4027 individuals, $3583(89.0 \%)$ had biochemical data available for analysis.

Study participants' socioeconomic, demographic, health, lifestyle, and family history characteristics are presented in Table 2 by country of residence and ethnic origin. U.S. non-Hispanic whites were older and had higher levels of smoking and alcohol consumption than Hispanics on both sides of the border. Hispanics on the U.S. side of the border had the highest BMI scores, the largest waist circumference, and the highest mean systolic blood pressure (SBP). Hispanics on the Mexican side of the border had the lowest level of education and socioeconomic status and reported markedly lower levels of physical activity compared with the other two groups.

As shown in Table 3, the overall crude prevalence of diabetes (both diagnosed and unrecognized) for the U.S.-Mexico border region was $16.8 \%$ (16.4\% for the Mexican side and $17.2 \%$ for the U.S. side). Hispanics on the Mexican side of the border had the highest prevalence of diabetes of all three groups (nonHispanic whites and Hispanics on the U.S. side of the border and Hispanics on the Mexican side of the border). Ageadjusted prevalence was $16.6 \%$ for Mexicans and $14.7 \%$ and $8.8 \%$ for Hispanics and non-Hispanic whites in the United States, respectively. Age-adjusted IFG prevalence was $14.1 \%$ for the Mexican side of the border and about the same for the U.S. side $(13.6 \%$ for Hispanics and $13.9 \%$ for non-Hispanic whites).

Results indicated that for every three people diagnosed with diabetes in the U.S.-Mexico border region there was one 
TABLE 2. Socioeconomic, demographic, health, lifestyle, and family history characteristics, by country of residence and ethnic origin, U.S.-Mexico border region, 2001-2002 ${ }^{\text {a }}$

\begin{tabular}{|c|c|c|c|c|}
\hline \multirow[b]{3}{*}{ Characteristic } & \multirow[b]{2}{*}{ Mexico } & \multicolumn{2}{|c|}{ United States } & \multirow[b]{3}{*}{$P$} \\
\hline & & \multirow[b]{2}{*}{ Hispanics $^{b}$} & \multirow{2}{*}{$\begin{array}{c}\text { Non-Hispanic } \\
\text { whites }^{c}\end{array}$} & \\
\hline & Hispanics & & & \\
\hline \multicolumn{5}{|l|}{ Sex $(\%)$} \\
\hline Male & $576(27.1)$ & $418(29.1)$ & $146(37.9)$ & \multirow[t]{2}{*}{$N A^{d}$} \\
\hline Female & $1546(72.9)$ & 1019 (70.9) & $239(62.1)$ & \\
\hline Age (years) (mean $\pm \mathrm{SD}^{\mathrm{e}}$ ) & $41 \pm 15$ & $46 \pm 17$ & $51 \pm 19$ & $<0.001^{f}$ \\
\hline \multicolumn{5}{|l|}{ Health measures (mean \pm SD) } \\
\hline Height (cm) & $159.0 \pm 9.1$ & $161.0 \pm 10.0$ & $168.0 \pm 10.0$ & $<0.001^{f}$ \\
\hline Weight (kg) & $73.1 \pm 15.5$ & $77.7 \pm 18$ & $80.7 \pm 20.5$ & $<0.001^{f}$ \\
\hline Body mass index & $28.9 \pm 5.8$ & $29.9 \pm 6.5$ & $28.7 \pm 7.5$ & $<0.001^{f}$ \\
\hline Waist circumference (cm) & $94.6 \pm 13.5$ & $96.7 \pm 15$ & $95.1 \pm 17.5$ & $0.001^{f}$ \\
\hline Waist-to-hip ratio & $0.89 \pm 0.08$ & $0.89 \pm 0.08$ & $0.89 \pm 0.09$ & $0.88^{f}$ \\
\hline \multicolumn{5}{|l|}{$\begin{array}{l}\text { Blood pressure }(\mathrm{mm} \mathrm{Hg}) \\
\text { (mean } \pm \mathrm{SD})\end{array}$} \\
\hline Systolic & $122.0 \pm 18.0$ & $126.0 \pm 19.0$ & $125.0 \pm 17.0$ & $<0.001^{f}$ \\
\hline Diastolic & $78.0 \pm 11.0$ & $79.0 \pm 11.0$ & $79.0 \pm 11.0$ & $0.06^{f}$ \\
\hline \multicolumn{5}{|l|}{ Smoking habit (\%) } \\
\hline Never smoked & 76.5 & 74.6 & 56.7 & \multirow{3}{*}{$<0.001^{g}$} \\
\hline Former smoker & 7.3 & 12.9 & 22.4 & \\
\hline Current smoker & 16.2 & 12.5 & 20.9 & \\
\hline \multicolumn{5}{|l|}{ Current drinker (including } \\
\hline occasional \& heavy drinker) (\%) & 27.6 & 39.0 & 53.0 & $<0.001^{9}$ \\
\hline \multicolumn{5}{|l|}{ Physical activity (\%) } \\
\hline Practice & 18.0 & 42.7 & 60.3 & \multirow[t]{2}{*}{$<0.001^{g}$} \\
\hline No regular activity & 82.1 & 57.3 & 39.7 & \\
\hline \multicolumn{5}{|l|}{ Education (\%) } \\
\hline$>12$ years & 7.0 & 15.4 & 53.3 & \multirow{4}{*}{$<0.001^{9}$} \\
\hline $7-12$ years & 39.0 & 51.9 & 46.2 & \\
\hline$\leq 6$ years & 46.3 & 29.5 & 0.5 & \\
\hline Illiterate & 7.7 & 3.2 & 0.0 & \\
\hline \multicolumn{5}{|l|}{ Socioeconomic status (\%) } \\
\hline High & 7.0 & 18.0 & 53.7 & \multirow{3}{*}{$<0.001^{\mathrm{g}}$} \\
\hline Medium & 70.1 & 63.0 & 46.1 & \\
\hline Low & 22.9 & 19.0 & 0.3 & \\
\hline \multicolumn{5}{|l|}{ Family history of diabetes (\%) } \\
\hline Yes & 40.3 & 49.3 & 36.1 & \multirow[t]{2}{*}{$<0.001^{g}$} \\
\hline No & 59.7 & 50.7 & 63.9 & \\
\hline \multicolumn{5}{|c|}{$\begin{array}{l}\text { a Based on the results of the U.S.-Mexico Di } \\
\text { b Individuals who reported being born in Mex } \\
\text { c Individuals who reported being born in the } \\
{ }^{d} \text { NA: not applicable. } \\
\text { e SD: standard deviation. } \\
{ }^{f} \text { Based on analysis of variance. } \\
{ }^{g} \text { Based on multinomial logistic regression. }\end{array}$} \\
\hline
\end{tabular}

person who was undiagnosed (i.e., 187 or $26.4 \%$ of the 709 participants with diabetes had not been previously diagnosed). Hispanics on the Mexican side of the border had the highest prevalence of undiagnosed diabetes $(34.8 \%$, or one out of every two people with diabetes) (Table 4), followed by Hispanics on the U.S. side of the border (18.9\%) (data not shown), and non-Hispanic whites had the lowest $(13.2 \%)$.

Among the participants in the current study, overall diabetes prevalence increased with age. Among study participants $\geq 60$ years old, one in three had diabetes. Of those with diabetes, regardless of age, $25.0 \%$ had a BMI score $\geq 30$ and $31.0 \%$ had a waist circumference $\geq 104 \mathrm{~cm}$ (i.e., more than one-fourth of those with diabetes in the study were obese) (Table 5).

Similarly, IFG prevalence rose with increases in BMI, waist circumference, waist-to-hip ratio, and SBP. However, no association was observed between IFG and either alcohol consumption or smoking. As with diabetes, IFG prevalence was inversely related with education (Table 5).

The study results confirmed the validity of many of the established risk factors for diabetes in the U.S.-Mexico border population. Based on logistic regression analysis, incidence of diabetes in the border region was associated with BMI, waist circumference, waist-to-hip ratio, SBP, smoking, education, and being Hispanic. As shown in Table 6, both crude ORs and those adjusted for age and selfreported diabetes diagnosis increased linearly with age, BMI, waist circumference, and waist-to-hip ratio. Many established risk factors for diabetes were also

TABLE 3. Crude and age-adjusted prevalence of diabetes and impaired fasting glucose (IFG), by country of residence and ethnic origin, U.S.Mexico border region, 2001-2002

\begin{tabular}{|c|c|c|c|c|c|c|c|c|c|}
\hline \multirow[b]{2}{*}{$\begin{array}{l}\text { Country of } \\
\text { residence }\end{array}$} & \multirow[b]{2}{*}{$\begin{array}{c}\text { Ethnic } \\
\text { origin }\end{array}$} & \multicolumn{4}{|c|}{ Cases with diabetes } & \multicolumn{4}{|c|}{ Cases with IFG ${ }^{b}$} \\
\hline & & $\begin{array}{c}\text { All } \\
\text { survey } \\
\text { respondents } \\
\text { No. }\end{array}$ & $\begin{array}{c}\text { Cases } \\
\text { of } \\
\text { diabetes }^{c} \\
\text { No. }\end{array}$ & $\begin{array}{c}\text { Crude } \\
\text { prevalence } \\
\%\end{array}$ & $\begin{array}{c}\text { Age- } \\
\text { adjusted } \\
\text { prevalence }^{\mathrm{d}} \\
\%\end{array}$ & $\begin{array}{c}\text { All } \\
\text { survey } \\
\text { respondents } \\
\text { No. }\end{array}$ & $\begin{array}{c}\text { Cases } \\
\text { of } \\
\text { diabetes }^{c} \\
\text { No. }\end{array}$ & $\begin{array}{c}\text { Crude } \\
\text { prevalence } \\
\%\end{array}$ & $\begin{array}{c}\text { Age- } \\
\text { adjusted } \\
\text { prevalence }^{d} \\
\%\end{array}$ \\
\hline Mexico & Hispanics & 2122 & 348 & 16.4 & 16.6 & 1774 & 245 & 13.8 & 14.1 \\
\hline United States & $\begin{array}{c}\text { Hispanics }^{e} \\
\text { Non-Hispanic whites }{ }^{f}\end{array}$ & $\begin{array}{r}1437 \\
385\end{array}$ & $\begin{array}{r}296 \\
53\end{array}$ & $\begin{array}{l}20.6 \\
13.8\end{array}$ & $\begin{array}{r}14.7 \\
8.8\end{array}$ & $\begin{array}{r}1141 \\
332\end{array}$ & $\begin{array}{r}175 \\
43\end{array}$ & $\begin{array}{l}15.3 \\
12.9\end{array}$ & $\begin{array}{l}13.6 \\
13.9\end{array}$ \\
\hline
\end{tabular}

a Based on the results of the U.S.-Mexico Diabetes Prevention and Control Project $(n=4$ 027).

${ }^{\mathrm{b}}$ Individuals with a fasting plasma glucose value of $5.6-6.9 \mathrm{mmol} / \mathrm{L}(100-125 \mathrm{mg} / \mathrm{dL}$ ) but no previous diagnosis of diabetes.

c Individuals who either self-reported a pre-study diabetes diagnosis by a health professional ("known diabetes") or had a fasting plasma glucose $\geq 7.0 \mathrm{mmol} / \mathrm{L}$ ( $126 \mathrm{mg} / \mathrm{dL}$ ) but were unaware of their diabetes ("newly diagnosed diabetes").

d Based on the World Health Organization standard population for the year 2000 (26)

e Individuals who reported being born in Mexico or identified themselves as Hispanics.

${ }^{f}$ Individuals who reported being born in the United States and identified themselves as non-Hispanic. 
TABLE 4. Diabetes prevalence by region/country of residence, ethnic origin, and diagnosis status, U.S.-Mexico border region, 2001-2002 ${ }^{\mathrm{a}}$

\begin{tabular}{|c|c|c|c|c|c|}
\hline \multirow[b]{2}{*}{ Country/region and ethnic origin } & \multirow[b]{2}{*}{ Total } & \multicolumn{2}{|c|}{ Diagnosed $^{b}$} & \multicolumn{2}{|c|}{ Undiagnosed } \\
\hline & & No. & $\%$ & No. & $\%$ \\
\hline U.S.-Mexico border regiond & 709 & 522 & 73.6 & 187 & 26.4 \\
\hline Mexicod & 348 & 227 & 65.2 & 121 & 34.8 \\
\hline United States $^{d}$ & 361 & 295 & 81.7 & 66 & 18.3 \\
\hline Hispanics ${ }^{e}$ & 296 & 240 & 81.1 & 56 & 18.9 \\
\hline Non-Hispanic whites ${ }^{f}$ & 53 & 46 & 86.8 & 7 & 13.2 \\
\hline
\end{tabular}

a Based on the results of the U.S.-Mexico Diabetes Prevention and Control Project $(n=4$ 027).

b Self-reported pre-study diabetes diagnosis by health professional ("known diabetes").

${ }^{c}$ In-study diabetes diagnosis based on biochemical data (fasting plasma glucose value $\geq 7.0 \mathrm{mmol} / \mathrm{L}$ [126 mg/dL]) among those previously unaware of their diabetes ("newly diagnosed diabetes")

d Including all ethnic groups.

e Individuals who reported being born in Mexico or identified themselves as Hispanics.

${ }^{f}$ Individuals who reported being born in the United States and identified themselves as non-Hispanics.

TABLE 5. Crude and adjusted odds ratio (OR) for diabetes in U.S.-Mexico border Hispanics versus U.S.-Mexico border non-Hispanic whites, ${ }^{a}$ by country of residence, U.S.-Mexico border region, 2001-2002

\begin{tabular}{|c|c|c|c|c|}
\hline \multirow[b]{2}{*}{ Variable } & \multicolumn{2}{|c|}{ Mexico } & \multicolumn{2}{|c|}{ United States } \\
\hline & OR & $95 \% \mathrm{Cl}^{\mathrm{C}}$ & OR & $95 \% \mathrm{Cl}$ \\
\hline Crude & 1.23 & $0.90-1.68$ & 1.63 & $1.18-2.23$ \\
\hline \multicolumn{5}{|l|}{ Adjusted for: } \\
\hline Sex & 1.25 & $0.91-1.71$ & 1.65 & $1.20-2.26$ \\
\hline Age & 2.26 & $1.62-3.15$ & 2.29 & $1.64-3.20$ \\
\hline Body mass index & 1.26 & $0.92-1.74$ & 1.56 & $1.13-2.16$ \\
\hline Waist circumference & 1.34 & $0.97-1.86$ & 1.62 & $1.16-2.26$ \\
\hline Waist-to-hip ratio & 1.28 & $0.93-1.77$ & 1.71 & $1.23-2.37$ \\
\hline Systolic blood pressure & 1.35 & $0.96-1.86$ & 1.60 & $1.15-2.22$ \\
\hline Diastolic blood pressure & 1.29 & $0.94-1.77$ & 1.69 & $1.23-2.34$ \\
\hline Family history of diabetes & 1.19 & $0.87-1.63$ & 1.47 & $1.07-2.03$ \\
\hline Use of tobacco & 1.23 & $0.90-1.68$ & 1.62 & $1.18-2.23$ \\
\hline \multicolumn{5}{|l|}{ Alcohol consumption } \\
\hline (including occasional \& heavy drinker) & 1.16 & $0.85-1.59$ & 1.59 & $1.16-2.19$ \\
\hline Education & 0.73 & $0.52-1.03$ & 1.14 & $0.82-1.58$ \\
\hline All variables above & 1.82 & $1.23-2.69$ & 1.81 & $1.25-2.63$ \\
\hline
\end{tabular}

\footnotetext{
a Reference group.

${ }^{\mathrm{b}}$ Based on the results of the U.S.-Mexico Diabetes Prevention and Control Project $(n=4$ 027).

${ }^{\mathrm{c}} \mathrm{Cl}$ : confidence interval.
}

associated with incidence of IFG in the region, including age, BMI, waist circumference, waist-to-hip ratio, family history of diabetes, and SBP, as well as smoking, alcohol consumption, and education, although the last three indicators were only weakly correlated.

\section{DISCUSSION}

The current study provides the first representative, population-based estimates of diabetes and IFG prevalence in the U.S.-Mexico border region. The overall rate of diabetes found in the study (crude prevalence of $17.6 \%, 95 \%$ confidence interval [CI] 16.4-18.8) is the highest ever reported in either Mexico or the United States, which had an estimated rate of $6.3 \%$ (27) for the same period as the study. In addition, the study's estimate of crude diabetes prevalence for the Mexican side of the border $(16.4 \%$, 95\% CI 14.8-18.0) was much higher than both the $7.5 \%$ rate reported in Mexico's National Health Survey for the year 2000 (28) and the $2.5 \%-3.2 \%$ rates reported for rural areas $(29,30)$ in studies among various groups of indigenous people (31, $32)$, and its age-adjusted rate $(16.6 \%)$ was much higher than the $10.7 \%$ figure reported for age-adjusted prevalence in selected urban areas in Mexico for the year 2000 (33).

According to one hypothesis, Hispanics in the Southern United States and those in Northern Mexico have more in common with each other than with the rest of the Hispanic population of Mexico. This idea was borne out in the current study results, in which age-adjusted diabetes prevalence was similar (and high) for Hispanics on both sides of the border. Diabetes prevalences for both groups of Hispanics along the U.S.-Mexico border are higher than those reported for Hispanics in other parts of the United States and Mexico. This high diabetes prevalence found in this study may be explained by a multifactorial model in which 1) predisposition to diabetes is determined by different combinations of genetic variants and environmental factors and 2) those with the genetic predisposition to developing the disease will only do so if they are exposed to the required environmental factors (34). Hispanics are assumed to have a particular predisposition, possibly on a genetic basis (35), to developing insulin resistance and diabetes when exposed to "adverse" conditions (34).

The U.S.-Mexico border region could be considered an obesogenic region (36) and therefore represents an adverse exposure for diabetes. Most Hispanics in the border region as well as other parts of the United States belong to the medium and lower socioeconomic classes, which have poor availability and access to highquality, reasonably priced foods. The inevitable development of "unhealthy" eating habits among these Hispanic groups often results in weight gain $(37,38)$. Another factor contributing to obesity among Hispanics in the United States, including those in the border region, is the increasing imbalance between calories consumed and calories expended. The amount of time spent on leisure-time physical activity is related not only to culture but also socioeconomic status. Neighborhoods with low socioeconomic status have a lower level of safety and less availability of and access to the manmade or natural environments that encourage or support leisure-time activities (39). Acculturation is another possible explanation for the high prevalence of obesity and diabetes among Hispanics. The process of acculturation affects Hispanics migrating from Central and Northern Mexico to various regions of the United States as well as those migrating from Central and Southern Mexico to the U.S.Mexico border region, where the influence of "Western culture" is very strong. Another potential contributing factor in the higher prevalence of diabetes along the border is the shift in the role of women from traditional home-based activities to participation in the workforce, which allows less time for preparing meals and therefore often results in the family's consumption of cheap fast food (40). 
TABLE 6. Age-adjusted odds ratio (OR) for diabetes and impaired fasting glucose (IFG), and per unit change, by characteristic, U.S.-Mexico border region, 2001-2002 ${ }^{\mathrm{a}}$

\begin{tabular}{|c|c|c|c|c|c|c|}
\hline \multirow[b]{2}{*}{ Characteristic } & \multicolumn{3}{|c|}{ Diabetes $(n=709)^{\mathrm{b}}$} & \multicolumn{3}{|c|}{ IFG $(n=475)^{b}$} \\
\hline & Cases (\%) & $\begin{array}{l}\text { Age-adjusted OR } \\
\left(95 \% \mathrm{Cl}^{\mathrm{C}}\right)\end{array}$ & $\begin{array}{l}\text { Age-adjusted OR } \\
(95 \% \mathrm{Cl}) \text { per } \\
\text { unit }^{d} \text { change }\end{array}$ & Cases (\%) & $\begin{array}{c}\text { Age-adjusted OR } \\
(95 \% \mathrm{Cl})\end{array}$ & $\begin{array}{c}\text { Age-adjusted OR } \\
(95 \% \mathrm{Cl}) \text { per } \\
\text { unit }^{\mathrm{d}} \text { change }\end{array}$ \\
\hline \multicolumn{7}{|l|}{ Sex } \\
\hline Male & $223(31.5)$ & 1 & $N A^{e}$ & $143(30.1)$ & 1 & NA \\
\hline Female & $486(68.5)$ & $1.01(0.84-1.22)$ & & $332(69.9)$ & $0.92(0.74-1.13)$ & \\
\hline \multicolumn{7}{|l|}{ Age (years) } \\
\hline$<29$ & $44(6.2)$ & 1 & 1 & $66(13.9)$ & 1 & 1 \\
\hline 30-39 & $85(12.0)$ & $2.02(1.38-2.94)$ & $1.25(1.22-1.28)$ & $106(22.3)$ & $1.77(1.28-2.45)$ & $1.12(1.08-1.15)$ \\
\hline $40-49$ & $127(17.9)$ & $3.98(2.78-5.69)$ & & $105(22.1)$ & $2.42(1.75-3.36)$ & \\
\hline $50-59$ & 169 (23.8) & $8.34(5.87-11.85)$ & & $94(19.8)$ & $3.71(2.64-5.22)$ & \\
\hline$\geq 60$ & $284(40.1)$ & 11.07 (7.91-15.48) & & $104(21.9)$ & $3.13(2.25-4.35)$ & \\
\hline \multicolumn{7}{|l|}{ Body mass index } \\
\hline 18.5-24.9 (normal weight) & $104(14.8)$ & 1 & 1 & $72(15.3)$ & 1 & 1 \\
\hline $25.0-29.9$ (overweight) & $230(32.8)$ & $1.37(1.06-1.78)$ & $1.06^{f}(1.05-1.08)$ & $144(30.6)$ & $1.36(1.01-1.84)$ & $1.06^{f}(1.05-1.08)$ \\
\hline$\geq 30$ (obesity) & $368(52.4)$ & $2.46(1.92-3.15)$ & & $255(54.1)$ & $2.96(2.23-3.91)$ & \\
\hline \multicolumn{7}{|l|}{ Waist circumference (cm) } \\
\hline$\leq 86$ & $76(10.8)$ & 1 & 1 & $81(17.1)$ & 1 & 1 \\
\hline $86-95$ & $140(19.9)$ & $1.92(1.42-2.59)$ & $1.199(1.16-1.23)$ & $101(21.3)$ & $1.50(1.10-2.04)$ & $1.15^{\mathrm{g}}(1.11-1.19)$ \\
\hline $95.1-104$ & 197 (28.0) & 2.49 (1.87-3.34) & & $126(26.5)$ & 1.99 (1.47-2.68) & \\
\hline$>104$ & $290(41.3)$ & $4.28(3.24-5.66)$ & & $167(35.1)$ & $3.27(2.44-4.38)$ & \\
\hline \multicolumn{7}{|l|}{ Waist-to-hip ratio } \\
\hline$\leq 0.833$ & $77(11.0)$ & 1 & 1 & $99(20.9)$ & 1 & 1 \\
\hline $0.834-0.8841$ & $135(19.2)$ & $1.74(1.29-2.35)$ & $1.05^{\mathrm{h}}(1.04-1.06)$ & $118(24.9)$ & $1.27(0.95-1.69)$ & $1.03^{\mathrm{h}}(1.01-1.04)$ \\
\hline $0.8842-0.941$ & $200(28.4)$ & 2.47 (1.86-3.29) & & $121(25.5)$ & 1.37 (1.03-1.83) & \\
\hline$>0.941$ & $291(41.4)$ & $3.29(2.49-4.36)$ & & $136(28.7)$ & $1.63(1.22-2.17)$ & \\
\hline \multicolumn{7}{|l|}{ Systolic blood pressure (mm Hg) } \\
\hline$<120$ & $146(21.3)$ & 1 & 1 & $151(32.7)$ & 1 & 1 \\
\hline $120-129$ & $140(20.4)$ & $1.34(1.04-1.73)$ & $1.13^{i}(1.08-1.19)$ & 107 (23.2) & $1.09(0.83-1.42)$ & $1.09^{i}(1.03-1.16)$ \\
\hline $130-139$ & $158(23.0)$ & $1.64(1.26-2.12)$ & & $96(20.8)$ & $1.28(0.96-1.71)$ & \\
\hline $140-159$ & $179(26.1)$ & $2.01(1.54-2.62)$ & & $81(17.5)$ & $1.30(0.95-1.79)$ & \\
\hline$\geq 160$ & $63(9.2)$ & $2.17(1.49-3.16)$ & & $27(5.8)$ & $1.45(0.89-2.37)$ & \\
\hline \multicolumn{7}{|l|}{ Family history } \\
\hline No & $280(39.5)$ & 1 & NA & $252(53.1)$ & 1 & NA \\
\hline Yes & $429(60.5)$ & 2.35 (1.99-2.77) & & $223(46.9)$ & $1.39(1.14-1.69)$ & \\
\hline \multicolumn{7}{|l|}{ Smoking status } \\
\hline Never smoked & $440(65.3)$ & 1 & 1 & $312(69.2)$ & 1 & 1 \\
\hline Former smoker & $122(18.1)$ & $1.40(1.09-1.80)$ & $1.13(1.01-1.27)$ & $66(14.6)$ & $1.51(1.11-2.06)$ & $1.10(0.97-1.26)$ \\
\hline Current smoker & $112(16.6)$ & $1.21(0.95-1.54)$ & & $73(16.2)$ & $1.13(0.86-1.49)$ & \\
\hline \multicolumn{7}{|l|}{ Alcohol consumption } \\
\hline Heavy (> 30 drinks/month) & 59 (8.3) & 1 & $\mathrm{NA}^{\mathrm{j}}$ & $47(9.9)$ & 1 & $\mathrm{NA}^{\mathrm{j}}$ \\
\hline Occasional ( $\leq 30$ drinks /month) & $134(18.9)$ & $1.12(0.80-1.57)$ & & $117(24.6)$ & $1.40(0.97-2.01)$ & \\
\hline Never & $515(72.8)$ & $1.46(1.08-1.97)$ & & $311(65.5)$ & $1.32(0.95-1.83)$ & \\
\hline \multicolumn{7}{|l|}{ Education } \\
\hline$>12$ years & $85(12.0)$ & 1 & 1 & $68(14.3)$ & 1 & 1 \\
\hline $7-12$ years & $250(35.4)$ & $1.22(0.92-1.61)$ & $1.22(1.09-1.36)$ & $212(44.7)$ & $1.19(0.89-1.61)$ & $1.01(0.89-1.15)$ \\
\hline$\leq 6$ years & $303(42.9)$ & $1.48(1.13-1.95)$ & & $170(35.9)$ & $1.13(0.83-1.54)$ & \\
\hline Illiterate & $69(9.7)$ & $1.82(1.24-2.68)$ & & $24(5.1)$ & $0.99(0.59-1.67)$ & \\
\hline
\end{tabular}

a Based on the results of the U.S.-Mexico Diabetes Prevention and Control Project ( $n=4027)$.

b Totals in each group vary as not all participants responded to all questions.

${ }^{\mathrm{c}} \mathrm{Cl}$ : confidence interval.

${ }^{d}$ Units are considered the categories of each characteristic, except when otherwise indicated.

e NA: not applicable.

${ }^{f}$ Increase by unit increase of body mass index.

9 Increase by $5 \mathrm{~cm}$.

${ }^{\mathrm{h}}$ Increase by 0.01 .

i Increase by $10 \mathrm{~mm} \mathrm{Hg}$.

j Nonlinear.

Among the current study participants, family history had the strongest association with diabetes. These results support familial aggregation of diabetes as evidence for a genetic contribution (41) among Mexicans on both sides of the border. In the 1980s, Gardner (42), Chakraborty (43), and Hanis (44) published evidence supporting the positive correlation between diabetes and Mexican-Americans' admixture of Europeans and Native Americans (45) in which the admixture could predispose them to insulin resistance and diabetes in the presence of an increased food supply.

According to the literature, individuals with IFG have a four to seven times higher risk for progressing to diabetes compared with people with normal glucose levels (46). In the current study, $14.3 \%$ (CI 13.1-15.6) of the participants were in this category.

This study has several limitations. First, it was conducted in 2001-2002, so the demographic and biological characteristics of the geographic areas that were studied and their respective diabetes and IFG 
prevalence could be different at present, although recent studies $(47,48)$ show results similar to those presented in the current research. Second, the Hispanics included in the current study were mainly of Mexican descent, $\geq 18$ years, and living in communities with $\geq 2500$ inhabitants along the U.S.-Mexico border, so the results presented here maybe not be valid for other groups of Hispanics in the United States (e.g., those living in Florida, Chicago, or New York). Third, based on the size of the current study's selected communities, people living in medium and large cities could have been overrepresented. Fourth, even though the study participants were allowed to choose either English or Spanish as their preferred survey language, information bias due to language difficulties (mainly on the U.S. side of the border) may have skewed some of the study results. Other potential study limitations include 1) the

1. International Diabetes Federation. IDF Diabetes Atlas. Executive summary. 2nd ed. Brussels: IDF; 2009.

2. Bloomgarden ZT. The epidemiology of complications. Diabetes Care. 2002;25(5):924-32.

3. Shai I, Jiang R. Manson JE, Stampfer MJ, Willett WC, Colditz GA, et al. Ethnicity, obesity and risk of type 2 diabetes in women: a 20-year follow-up study. Diabetes Care. 2006; 29(7):1585-90.

4. King H, Aubert RE, Herman WH. Global burden of diabetes, 1995-2025: prevalence, numerical estimates, and projections. Diabetes Care. 1998;21(9):1414-31.

5. Wannamethee SG, Shaper A. Weight change and duration of overweight and obesity in the incidence of type 2 diabetes. Diabetes Care. 1999;22(8):1266-72.

6. Van Dam RM. The epidemiology of lifestyle and risk for type 2 diabetes. Eur J Epidemiol. 2003;18(12):1115-25.

7. D'Agostino RB Jr, Hamman RF, Karter AJ, Mykkanen L, Wagenknecht LE, Haffner SM, et al. Cardiovascular disease risk factors predict the development of type 2 diabetes: the insulin resistance atherosclerosis study. Diabetes Care. 2004;27(9):2234-40.

8. Connolly V, Unwin N, Sherriff P, Bilous R, Kelly W. Diabetes prevalence and socioeconomic status: a population based study showing increased prevalence of type 2 diabetes mellitus in deprived areas. J Epidemiol Community Health. 2000;54(3):173-7.

9. Robbins JM, Vaccarino V, Zhang H, Kasi SV. Excess type 2 in African-American women and men aged 40-74 and socioeconomic status: evidence from the Third National Health and Nutrition Examination Survey. J Epidemiol Community Health. 2000;54(11): 839-45.

10. Kumari M, Head J, Marmot M. Prospective study of social and other risk factors for fact that no oral glucose tolerance tests were conducted, creating the possibility that actual diabetes prevalence was even more widespread than indicated by the already-high rates reported in the study, and 2) the cross-sectional nature of the study, which limited the possibility of drawing causal relationships between the risk factors and both diabetes and IFG. Nevertheless, this study is one of the largest to date to assess the prevalence of diabetes in the noninstitutionalized population in counties and municipalities along the U.S.-Mexico border. It should be noted that the high prevalence of diabetes found in the current study for this region may be partially attributable to the fact that the results are based not only on self-reported diagnosis of diabetes but also on biochemical results of those not previously diagnosed.

The high levels of diagnosed diabetes and IFG found in the current study are

\section{REFERENCES}

incidence of type 2 diabetes in the Whitehall II study. Arch Intern Med. 2004;164(17): 1873-80.

11. Aguilar-Salinas CA, Velázquez-Monroy $\mathrm{O}$, Gómez-Pérez FJ, González-Chávez A, Esqueda AL, Molina-Cuevas V, et al. Characteristics of patients with type 2 diabetes in México. Results from a large populationbased nationwide survey. Diabetes Care. 2003;26(7):2021-6.

12. Secretaría de Salud, Dirección General de Información en Salud (MX). Principales causas de mortalidad 2004. México, D.F.: SSA, SINAIS; 2006.

13. Miniño AM, Heron MP, Smith BL. Deaths: preliminary data for 2004. Natl Vital Stat Rep. 2006;54(19):1-49.

14. Ramachandran A, Snehalatha C, Kapur A, Vijay V, Mohan V, Das AK, et al. High prevalence of diabetes and impaired glucose tolerance in India: National Urban Diabetes Survey. Diabetologia. 2001;44(9):1094-101.

15. U.S. Centers for Disease Control and Prevention. Prevalence of diabetes among Hispanics—selected areas, 1998-2002. MMWR Morb Mortal Wkly Rep. 2004;53(40):941-4.

16. U.S. Centers for Disease Control and Prevention. Prevalence among American Indians and Alaska Natives and the overall population-United States, 1994-2002. MMWR Morb Mortal Wkly Rep. 2003;52(30):702-4.

17. Miniño AM, Heron MP, Murphy SL, Kochanek KD. Deaths: Final data for 2004. Natl Vital Stat Rep. 2007;55(19):1-120.

18. U.S. Census Bureau. America at the dawn of a new century. In: Population profile of the United States 2000. Part I [monograph on the Internet]. Washington, D.C.: Government Printing Office; 2005. Available from: http: / / www.census.gov/population/www / pop-profile/profile2000.html. Accessed 15 July 2008. likely to lead to increased levels of health complications and health care needs as the population ages and indicate that border area health systems are not making adequate attempts to screen populations for these conditions.

Acknowledgments. The authors thank Rita Diaz-Kenney, Gloria Beckles, Rodolfo Valdez, and other staff from the U.S. Centers for Disease Control and Prevention who provided support to the U.S.Mexico Diabetes Prevention and Control Project; the staff of both the Primus Diagnostics laboratory in Kansas City, Missouri (USA) and Mexican ministry of health (Secretaría de Salud); and all individuals and institutions in the 10 border states that work and support the project (Arizona, California, New Mexico, and Texas, in the United States, and Baja California, Chihuahua, Coahuila, Nuevo León, Sonora, and Tamaulipas, in Mexico).

19. New Mexico Department of Health, Bureau of Vital Records and Health Statistics, Epidemiology and Response Division. Birth and mortality monograph. 2004 preliminary data. Santa Fe, NM: NMDH, BVRHS; 2005.

20. Texas Department of State Health Services. Texas vital statistics. 2004 summary. Austin, TX: TDSHS; 2005 [updated 2007 Jul 5]. Available from: http: / / www.dshs.state.tx.us / chs / vstat/vs04/anrpt.shtm. Accessed 15 February 2008.

21. California Department of Health Services. Vital statistics of California, 2003. Sacramento, CA: CDHS; 2005.

22. Arizona Department of Health Services. Arizona vital statistics: differences in the health status among race/ethnic groups 2003. Phoenix, AZ: ADHS; 2005. Available from: http:/ / www.azdhs.gov/plan/ report/dhsag/ dhsag03/ethnic03.pdf. Accessed 15 March 2008.

23. Instituto Nacional de Estadística Geografía e Informática (MX). Defunciones generales por causas 2006 - por entidad. Aguascalientes: INEGI; 2008.

24. World Health Organization; International Diabetes Federation. Definition and diagnosis of diabetes mellitus and intermediate hyperglycemia: report of a WHO/IDF consultation. Geneva: WHO; 2006.

25. Chobanian AV, Bakris GL, Black HR, Cushman WC, Green LA, Izzo JL Jr, et al. Seventh report of the Joint National Committee on Prevention, Detection, Evaluation, and Treatment of High Blood Pressure. Hypertension. 2003;42(6):1206-52.

26. Ahmad O, Boschi-Pinto C, Lopez AD, Murray CJL, Lozano R, Inoue M. Age standardization of rates: a new WHO standard. Geneva: World Health Organization; 2001. Available from www.who.int/healthinfo/ paper31.pdf. Accessed 20 September 2010. 
27. U.S. Centers for Disease Control and Prevention. National diabetes fact sheet: general information and national estimates on diabetes in the United States, 2003. Rev. ed. Atlanta, GA: U.S. Department of Health and Human Services, CDC; 2004. Available from: http:// www.cdc.gov/diabetes/pubs / factsheet03. $\mathrm{htm}$. Accessed 15 November 2007.

28. Olaiz G, Rojas R, Barquera S, Shamah T, Aguilar C, Cravioto P, et al. Encuesta Nacional de Salud 2000. Tomo 2: la salud de los adultos. Cuernavaca: Instituto Nacional de Salud Pública; 2003.

29. Schulz LO, Bennett PH, Ravussin E, Kidd JR, Kidd KK, Esparza J, et al. Effects of traditional and western environments on prevalence of type 2 diabetes in Pima Indians in Mexico, and in the US. Diabetes Care. 2006;29(8):1866-71.

30. Guerrero Romero JF, Rodríguez Moran M, Sandoval Herrera F. Prevalencia de diabetes mellitus no insulinodependiente en la población rural de Durango, México. Rev. Panam Salud Publica, 1997;2(6):389-91.

31. Alvarado-Osuna C, Milian-Suazo F, VallesSánchez V. Prevalencia de diabetes mellitus e hiperlipidemias en indígenas otomíes. Salud Publica Mex. 2001;43(5):459-63.

32. Castro Sánchez H, Escobedo de la Peña J. La prevalencia de la diabetes mellitus no dependiente de insulina y factores de riesgo asociados, en población mazateca del estado de Oaxaca, México. Gac Med Mex. 1997;133(6): 527-34.

33. Lara A, Rosas M, Pastelín G, Aguilar C, Attie F, Velázquez Monroy O. Hipercolesterolemia e hipertensión arterial en México: Consolidación urbana actual con obesidad, diabetes y tabaquismo. Arch Cardiol Mex. 2004;74(3): 231-45.
34. Van Tilburg J, van Haeften TW, Pearson P, Wijmenga C. Defining the genetic contribution of type 2 diabetes mellitus. J Med Genet. 2001;38(9):569-78.

35. Permutt MA, Wasson J, Cox N. Genetic epidemiology of diabetes. J Clin Invest. 2005;115 (6):1431-9.

36. Swinburn B, Egger G, Raza F. Dissecting obesogenic environments: the development and application of a framework for identifying and prioritizing environmental interventions for obesity. Prev Med. 1999;29 (6 Pt 1):563-70.

37. Morland K, Wing S, Diez Roux AC, Poole C. Neighborhood characteristics associated with the location of food stores and food service places. Am J Prev Med. 2002;22(1):23-9.

38. Rose D, Richards R. Food store access and household fruit and vegetables use among participants in the US Food Stamp Program. Pub Health Nutr. 2004;7(8):1081-8.

39. Jones A, Bentham G, Foster C, Hillsdon M, Panter J. Tackling obesities: future choicesobesogenic environments. Evidence review. London: Government Office for Science, Foresight Programme; 2006. Available from: http:/ / www.foresight.gov.uk/Obesity/03.p df. Accessed 15 September 2008.

40. Prentice AM, Jebb SA. Fast foods, energy density and obesity: a possible mechanistic link. Obes Rev. 2003;4(4):187-94.

41. Barroso I. Genetics of type 2 diabetes. Diabet Med. 2005;22(5):517-35.

42. Gardner LI Jr, Stern MP, Haffner SM, Gaskill SP, Hazuda HP, Relethford JH, et al. Prevalence of diabetes in Mexican Americans. Relationship to percent of gene pool derived from Native American sources. Diabetes. 1984;33 (1):86-92.
43. Chakraborty R, Ferrell RE, Stern MP, Haffner SM, Hazuda HP, Rosenthal M. Relationship of prevalence of non-insulin-dependent diabetes mellitus to Amerindian admixture in the Mexican Americans of San Antonio, Texas. Genet Epidemiol. 1986;3(6):435-54.

44. Hanis CL, Hewett-Emmett D, Bertin TK, Schull WJ. Origins of U.S. Hispanics. Implications for diabetes. Diabetes Care. 1991;14(7): 618-27.

45. Meigs JB, Cupples LA, Wilson PW. Parental transmission of type 2 diabetes: the Framingham Offspring Study. Diabetes. 2000;49(12): 2201-7.

46. Gerstein HC, Santaguida $P$, Raina $P$, Morrison KM, Balion C, Hunt D, et al. Annual incidence and relative risk of diabetes in people with various categories of dysglycemia: a systematic overview and meta-analysis of prospective studies. Diabetes Res Clin Pract. 2007;78(3):305-12.

47. Fisher-Hoch SP, Rentfro AR, Salinas JJ, Pérez A, Brown HS, Reininger BM, et al. Socioeconomic status and prevalence of obesity and diabetes in a Mexican American community, Cameron County, Texas, 2004-2007. Prev Chronic Dis. 2010;7(3):A53.

48. Ory MG, Conkling M, Bolin JN, Prochaska JD, Zhan D, Burdine JN, et al. Sociodemographic and healthcare characteristics of Colonia residents: the role of life stage in predicting health risks and diabetes status in a disadvantaged Hispanic population. Ethn Dis. 2009;19(3):280-7.

Manuscript received on 23 March 2010. Revised version accepted for publication 10 August 2010.
RESUMEN

\section{Prevalencia de diabetes tipo 2 y de alteración de la glucosa en ayunas: estudio transversal de una población adulta multiétnica en la frontera México-Estados Unidos}

Objetivo. Calcular la prevalencia de la diabetes de tipo 2 (diabetes) y de la alteración de la glucosa en ayunas en la zona fronteriza entre México y los Estados Unidos, por origen étnico y país de residencia; identificar los factores de riesgo asociados a ambas afecciones, y explorar en qué grado estos factores explican las diferencias transfronterizas o étnicas en la prevalencia.

Métodos. Entre abril del 2001 y noviembre del 2002, se realizó la fase I del Proyecto de Prevención y Control de la Diabetes en la Frontera México-Estados Unidos, un estudio de prevalencia de la diabetes y sus factores de riesgo, mediante un muestreo por conglomerados en varias fases. Se utilizó un cuestionario acerca de la diabetes (autonotificada) y el modo de vida, se realizó una exploración física y se extrajo una muestra de sangre. En total, participaron 4027 adultos en el estudio: 2120 hispanos del lado mexicano de la frontera, y 1437 y 470 no hispanos (de los cuales, 385 se clasificaron como "blancos") del lado estadounidense de la frontera.

Resultados. La prevalencia (ajustada según la edad) de la diabetes autonotificada y no diagnosticada en los hispanos fue de $15,4 \%$ (16,6\% en el lado mexicano de la frontera y $14,7 \%$ en el lado estadounidense). La prevalencia (ajustada según la edad) de la alteración de la glucosa en ayunas fue similar en ambos lados de la frontera $(14,1 \%$ en el lado mexicano y 13,6\% en el lado estadounidense).

Conclusiones. Los factores de riesgo conocidos para la diabetes (por ejemplo edad, obesidad y antecedentes familiares) resultaron relevantes y hubo una relación inversa entre la diabetes y el nivel socioeconómico y la escolaridad. Si bien la prevalencia de la diabetes es alta en ambos lados de la frontera entre México y los Estados Unidos, un cuarto de los casos sigue sin diagnóstico, lo que indica la necesidad de crear y ejecutar un programa de salud pública para la prevención, el diagnóstico y el control de la diabetes en la zona.

Diabetes mellitus tipo 2; prevalencia; salud fronteriza; México; Estados Unidos. 